\title{
Nonsyndromic Hypodontia: A Case Report
}

\author{
Unnat Dhanwani ${ }^{1}$, Nikita Sobti ${ }^{2}$, Shantanu Jain $^{3}$, Anjali Uttwani $^{4}$
}

\begin{abstract}
Hypodontia is the most common anomaly in human dentition associated with number that develops in the initiation stage of tooth morphogenesis. It is characterized by tooth agenesis of two to six teeth, may or may not be associated with a syndrome, and is controlled by a combination of genetic and environmental factors. Mutations in the genes MSX 1 and PAX 9, which are the main genes responsible for odontogenesis, are responsible for the development of nonsyndromic hypodontia. In this case report, a 13-year-old girl reported to the Department of Pediatric and Preventive Dentistry with the complaint of midline diastema. On clinical and radiographic examination, she was diagnosed with this condition and was explained about the treatment prospects.

Keywords: Developmental anomaly, Midline diastema, Nonsyndromic hypodontia.

Journal of Mahatma Gandhi University of Medical Sciences \& Technology (2019): 10.5005/jp-journals-10057-0111
\end{abstract}

\section{INTRODUCTION}

Hypodontia is reported to be the most prevalent dental malformation in humans. It is a type of tooth agenesis that results because of the failure of formation of two to six teeth, while the term oligodontia is used to describe a tooth agenesis with more than six missing teeth. Anodontia on the other hand refers to the developmental failure of the entire dentition.

Hypodontia is a rare occurrence in the deciduous dentition with a prevalence rate of $0.1-0.9 \%$. $^{1}$ The deciduous maxillary lateral and mandibular central incisors account for $50-90 \%$ of affected deciduous teeth. ${ }^{2}$ Hypodontia is a relatively common developmental anomaly in permanent dentition. The prevalence of hypodontia, which may be increasing with time, ranges from 1.6 to $36.5 \%$ depending on the population studied. Mandibular second premolars and the maxillary lateral incisors have been reported to be the most likely to be missing teeth. ${ }^{3,4}$ Several studies have also found that hypodontia has a female predilection.

This report presents a case of nonsyndromic hypodontia with four permanent teeth missing.

\section{Case Description}

A 13-year-old girl reported to the Department of Pediatric and Preventive Dentistry with the complaint of midline diastema and wished to get the diastema closed.

While performing intraoral examination, tooth agenesis in the patient was suspected which was diagnosed with the help of clinical and radiographic findings. The number of missing teeth were noted, and third molars were excluded. Intraoral examination of the patient revealed four permanent missing teeth (Figs 1 and 2). The clinical findings were confirmed with the help of radiographic examination by an orthopantomogram which was helpful in determining the eruptive status of the other permanent teeth and in confirming the case of hypodontia (Fig. 3). It was observed that the maxillary lateral incisors and canines of the either side were missing. There was spacing in-between the maxillary central incisors and between the first premolar and central incisors on left side and in-between central incisors and deciduous canine on the right side. The maxillary first premolar on the left side was also distobuccally rotated. The only deciduous tooth present in the oral cavity was
${ }^{1-3}$ Department of Pediatric and Preventive Dentistry, Mahatma Gandhi Dental College and Hospital, Puducherry, India

${ }^{4}$ Department of Orthodontics and Dentofacial Orthopedics, Mahatma Gandhi Dental College and Hospital, Puducherry, India

Corresponding Author: Unnat Dhanwani, Department of Pediatric and Preventive Dentistry, Mahatma Gandhi Dental College and Hospital, Puducherry, India, Phone: +91 7062672574, e-mail: unnatidhanwan092@gmail.com

How to cite this article: Dhanwani U, Sobti N, Jain S, et al. Nonsyndromic Hypodontia: A Case Report. J Mahatma Gandhi Univ Med Sci Tech 2019;4(3):74-76.

Source of support: Nil

Conflict of interest: None

right maxillary canine. Extraoral examination of the patient did not reveal any significant finding.

Since the main complaint of the patient was of a midline diastema, she was referred to the Department of Orthodontics for further treatment.

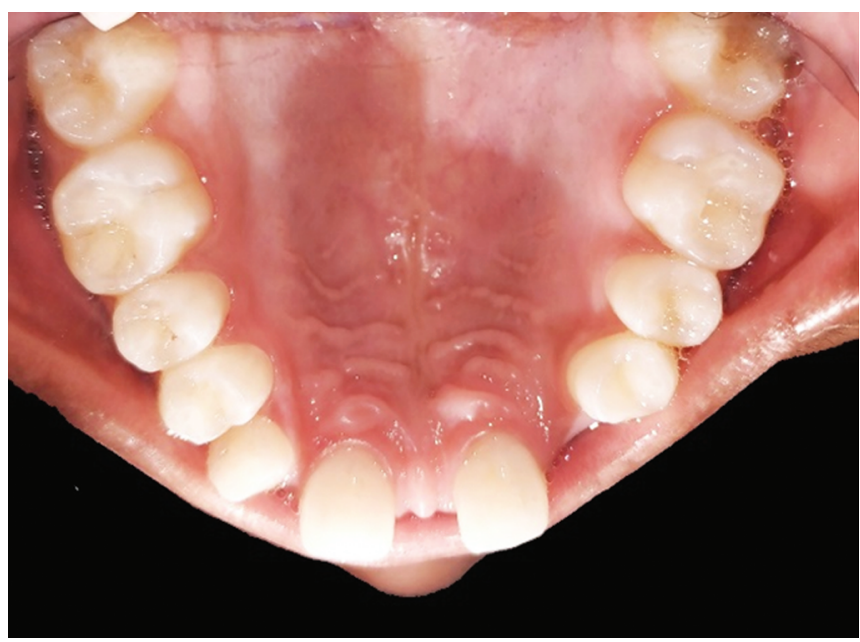

Fig. 1: Maxillary arch of the patient with a midline diastema, spaces between the central incisor and canine and in-between the central incisor and the premolar. The first premolar is distobuccally rotated

() The Author(s). 2019 Open Access This article is distributed under the terms of the Creative Commons Attribution 4.0 International License (https://creativecommons. org/licenses/by-nc/4.0/), which permits unrestricted use, distribution, and non-commercial reproduction in any medium, provided you give appropriate credit to the original author(s) and the source, provide a link to the Creative Commons license, and indicate if changes were made. The Creative Commons Public Domain Dedication waiver (http://creativecommons.org/publicdomain/zero/1.0/) applies to the data made available in this article, unless otherwise stated. 


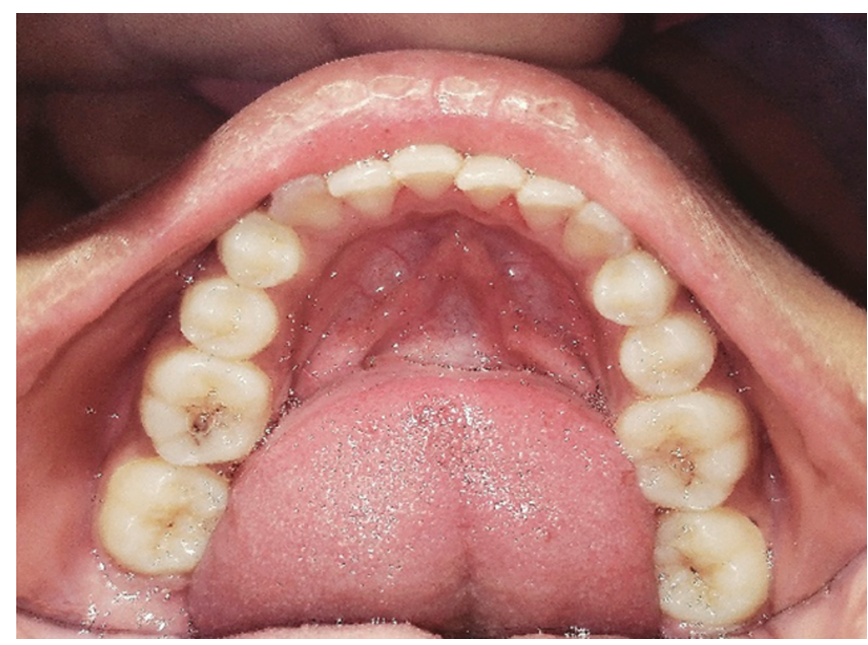

Fig. 2: Mandibular arch of the patient showing no anomalies

\section{Discussion}

Development of tooth is a complex process that involves interactions between mesenchymal, ectodermal, and the neural crest cells that regulate the tooth morphogenesis. Hypodontia is a developmental anomaly that has a multifactorial etiology involving both genetic and environmental factors. It can be an isolated trait or can be associated with several other developmental anomalies such as cleft lip and palate, ectodermal dysplasia, taurodontism, and altered craniofacial growth that is mostly associated with permanent dentition and has a higher predilection for females. Nonsyndromic hypodontia is the most common form of congenital absence that can involve various teeth.

Hypodontia is widely characterized by the presence of microdontia, ectopic positioning of permanent teeth, generalized spacing in teeth, and rotated teeth. Nonsyndromic hypodontia is classified as a sporadic or familial form, inherited in an autosomal-dominant, autosomal-recessive, or X-linked mode, with considerable variation in both penetrance and expressivity. ${ }^{5}$ Tooth agenesis is also associated with enamel hypoplasia, diminutive or peg maxillary lateral incisors, primary molar infraocclusion, and palatally inclined or impacted maxillary canines. ${ }^{6,7}$ Intraorally, retroclined and overerupted lower incisors contribute to a greater overbite. ${ }^{8}$ Patients with hypodontia present with low mandibular plane angles, shorter maxillary and mandibular lengths, and an Angle's Class III molar relationship features.

Many genes have been identified that play a role in tooth morphogenesis including determination of the tooth size, extent, shape, and location. MSX 1 gene is responsible for the development of ectodermal derivatives and is strongly expressed in the dental mesenchyme. ${ }^{9}$ Another gene called as PAX 9 gene is the key controlling factor in tooth morphogenesis. $P A X 9$ regulates functions of MSX 1. Mutations of PAX9 cause abnormal or reduced downstream protein regulation function which is important for tooth development and is linked to nonsyndromic hypodontia.

According to a review by Lamour et al., majority of hypodontia patients reported only 1 or 2 missing teeth with few cases showing 4 or more missing teeth and only fewer presenting 6 or more missing teeth. ${ }^{10}$ This patient has four permanent missing teeth which is a rare occurrence. Numerous studies demonstrated higher frequency of hypodontia and microdontia in females (McKeown et al., Neville et al., Larmour et al. $)^{10-12}$ Contrarily, few authors noted that anomalies

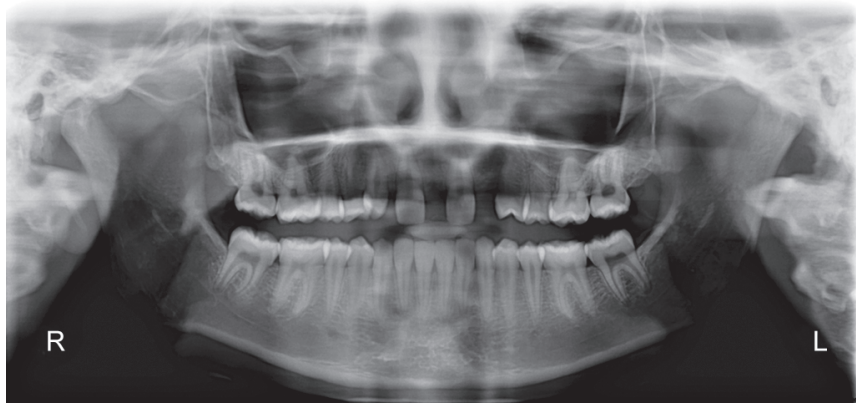

Fig. 3: Orthopantomogram of the patient confirming the clinical findings

were more frequent in male patients than in females (Sisman et al., Tallón-Walton et al.). ${ }^{13,14}$ There has been a link between microdontia with hypodontia as suggested by Shafer et al. ${ }^{15}$ and Altug-Atac and Erdem. ${ }^{16}$ This patient did not show generalized or localized microdontia. It has also been put forward by Baccetti ${ }^{17}$ that pegshaped upper lateral incisors; impacted canines, rotated bicuspids, and short root anomaly are caused by the same genetic elements responsible for agenesis of incisors and premolars. In this case, the patient had distobuccally rotated right mandibular first premolar.

Hypodontia is also associated with poor esthetics due to generalized/localized spacing, microdontia, peg laterals, midline diastema, and rotated teeth. It can also interfere with articulation and speech and hence is necessary to get treated.

\section{Treatment Regimens}

This patient was referred to the Department of Orthodontics for the closure of midline diastema and other spaces. Factors such as patient's age, financial status, and extent of the defect determine the treatment plan. In this case, patient's maxillary arch shows a midline diastema and space in-between the maxillary centrals and the maxillary deciduous canine on the right and maxillary first premolar on the left. Following is the suggested treatment plan:

- Space optimization: Space can be gained in the maxillary arch after closure of midline diastema and derotation of maxillary first premolar.

- Space utilization: After space has been gained, it can be utilized with the help of implants or a fixed partial denture or a removable partial denture. The selection of the treatment option among these three is dependent upon patient's financial status and their awareness about the condition.

\section{Conclusion}

Hypodontia may be a common developmental anomaly, but moderate hypodontia characterized by the agenesis of more than two and less than six teeth is a less frequent scenario to encounter. It is mostly not associated with any syndrome but should still be taken into consideration for treatment. The dentist should make the patient aware about the disturbances that can be caused if this condition is not treated as soon as it is diagnosed. Various treatment options should be explained to the patient who can help achieve the prosthetic and esthetic functionality of teeth.

\section{References}

1. Guruprasad R, Nair PP, Hegde K, et al. Nonsyndromic oligodontia-A case report. J Indian Dent Assoc 2011;3:450-453. 
2. Nieminen P. Genetic basis of tooth agenesis. J Exp Zool B Mol Dev Evol 2009;312(4):320-342. DOI: 10.1002/jez.b.21277.

3. Polder BJ, Van't Hof MA, Van Der Linden FPGM, et al. A meta-analysis of the prevalence of dental agenesis of permanent teeth. Community Dent Oral Epidemiol 2004;32(3):217-226. DOI: 10.1111/j.16000528.2004.00158.x.

4. Symons AL, Stritzel F, Stamation J. Anomalies associated with hypodontia of the permanent lateral incisor and second premolar. J Clin Pediatr Dent 1993;17(2):109-111.

5. Burzynski NJ, Escobar VH. Classification and genetics of numeric anomalies of dentition. Birth Defects Orig Artic Ser 1983;19(1): 95-106.

6. Baccetti T. Tooth rotations associated with tooth agenesis. Angle Orthod 1998;68(3):267-274.

7. Pirinen $S$, Kentala $A$, Nieminen $P$, et al. Recessively inherited lower incisor hypodontia. J Med Genet 2001;38(8):551-556. DOI: 10.1136/ jmg.38.8.551.

8. Carter NE, Gillgrass TJ, Hobson RS, et al. The interdisciplinary management of hypodontia: orthodontics. Br Dent J 2003;194(7):361366. DOI: $10.1038 /$ sj.bdj.4809995.

9. Vieira AR, Meira R, Modesto A, et al. MSX1, PAX9, and TGFa contribute to tooth agenesis in humans. J Dent Res 2004;83(9):723-727. DOI: 10.1177/154405910408300913.
10. Larmour CJ, Mossey PA, Thind BS, et al. Hypodontia-a retrospective review of prevalence and etiology. Part I. Quintessence Int 2005;36(4):263-270.

11. McKeown HF, Robinson DL, Elcock C, et al. Tooth dimensions in hypodontia patients, their unaffected relatives and a control group measured by a new image analysis system. Eur J Orthod 2002;24(2):131-141. DOI: 10.1093/ejo/24.2.131.

12. Neville DW, Damm DD, Allen CM, et al. Abnormalities of teeth. OIndian Journal of Dental Sciences. Oral and Maxillofacial Pathology. 2nd ed., Philadelphia: Elsevier; 2005. pp. 49-89.

13. Sisman Y, Uysal T, Gelgor IE. Hypodontia. Does the prevalence and distribution pattern differ in orthodontic patients? Eur J Dent 2007;1(3):167-173. DOI: 10.1055/s-0039-1698333.

14. Tallón-Walton V, Nieminen P, Arte S, et al. An epidemiological study of dental agenesis in a primary health area in Spain: estimated prevalence and associated factors. Med Oral Patol Oral Cir Bucal 2010;15(4):569-574. DOI: 10.4317/medoral.15.e569.

15. Shafer WG, Hine MK, Levy BM, et al. Text Book of Oral Pathology. 4th ed., Philadelphia: Sanders; 1993.

16. Altug-Atac AT, Erdem D. Prevalence and distribution of dental anomalies in orthodontic patients. Am J Orthod Dentofacial Orthop 2007;131(4):510-514. DOI: 10.1016/j.ajodo.2005.06.027.

17. Baccetti T. A controlled study of associated dental anomalies. Angle Orthod 1998;68(3):267-274. 